\title{
Study of Various Prognostic Factors Affecting Successful Myringoplasty in a Tertiary Care Centre
}

\author{
Kripa Dangol ${ }^{1}$ Rakesh Prasad Shrivastav ${ }^{1}$ \\ ${ }^{1}$ Department of Ganesh Man Singh Memorial Academy of Ear, Nose, \\ Throat - Head and Neck Surgery, Institute of Medicine, Maharajgunj, \\ Kathmandu, Nepal \\ Int Arch Otorhinolaryngol 2017;21:250-254.
}

\begin{abstract}
Address for correspondence Kripa Dangol, MBBS, MSc ENT-HNS, Department of Ganesh Man Singh Memorial Academy of Ear, Nose, Throat - Head and Neck Surgery, Institute of Medicine, Maharajgunj, Kathmandu 44613, Nepal (e-mail: kripabibek@outlook.com).
\end{abstract}

\begin{abstract}
Introduction Myringoplasty is a commonly performed otologic surgery. Objectives The objective of this study is to evaluate the effect of prognostic factors like - size, site of perforation, status of operating ear, approach, status of contralateral ear, experience of surgeon, primary or revision myringoplasty, and smoking in graft uptake, as well as to evaluate the hearing results after myringoplasty.

Methods This is a prospective study. We included in our sample patients aged over 13 years with a Tubotympanic Chronic Otitis Media diagnosis. The patients underwent preoperative evaluation and Pure Tone Audiogram within one week prior to surgery. We performed myringoplasty using temporalis fascia graft with conventional underlay technique. We evaluated postoperative graft uptake and various factors related to the study and did a Pure Tone Audiogram at one year after surgery.

Results The graft uptake rate after myringoplasty was $83.1 \%$ at one year in 219 patients. Graft uptake with normal opposite ear was $88.2 \%$, and with Tubotympanic Chronic Otitis Media was 75\% (statistically significant). We found no statistically significant difference in graft uptake results with other factors. We calculated hearing results of 132 patients with normal ossicular status who underwent myringoplasty. The average Air Conduction Threshold improvement was $11.44 \mathrm{~dB}(p<0.001)$ and the

\section{Keywords}

- myringoplasty

- fascia

- tympanic membrane perforation average Air-Bone Gap closure was $8.89 \mathrm{~dB}$, highly statistically significant $(p<0.001)$. Conclusion Diseased contralateral ear was a statistically significant poor prognostic factor for graft uptake after myringoplasty. Other factors studied were not statistically significant determining factor for graft uptake. Hearing improves significantly after myringoplasty if the ossicles are normal.
\end{abstract}

\section{Introduction}

Chronic Otitis Media (COM) is the disease of the middle ear cleft with the permanent abnormality of pars tensa or pars flaccida. ${ }^{1}$ COM is an important cause of preventable hearing loss, particularly in the developing world. ${ }^{2}$ In Nepal, $3.04 \%$ of the population above 5 years of age have tubotympanic COM. ${ }^{3}$ Tubotympanic Chronic Otitis Media (previously termed as simple or noncholesteatomatous type of $\mathrm{COM}$ ) encompasses cases with central perforation in the pars tensa of the tympanic membrane. The

received

September 16, 2015 accepted

September 18, 2016

published online

November 28, 2016 10.1055/s-0036-1593818. ISSN $1809-9777$. surgical treatment for tubotympanic COM is myringoplasty. Myringoplasty is the simple repair of a tympanic membrane (TM) perforation in which no ossicular reconstruction is involved. ${ }^{4}$ The purpose of the surgery is to repair pars tensa perforation and thus eliminate the susceptibility to middle ear infections and improve hearing. Myringoplasty prevents migration of squamous epithelium in the middle ear and thus cholesteatoma formation..$^{5}$ It helps to prevent further hearing loss which may occur in a chronically discharging ear due to resorptive osteitis of the ossicles. ${ }^{1}$

Copyright $\odot 2017$ by Thieme Revinter

Publicações Ltda, Rio de Janeiro, Brazil
License terms

() (1) $\Theta \circledast$ 
Myringoplasty was first performed by Berthold using full thickness skin graft in 1878 and the operation was called "myringoplastik." ${ }^{6}$ Heermann introduced temporalis fascia as a graft in 1958. This is still the most popular grafting material followed by perichondrium and cartilage. The advantages of temporalis fascia include the ease of harvest, availability of large amount of graft, and very high take rates without subsequent problems when used to close simple perforation.

There is a long-standing debate regarding factors that affect successful closure of perforation such as - age, size, and site of perforation, duration of dry period prior to surgery, surgical approach and technique, status of the contralateral ear, status of the middle ear at surgery, experience of surgeon, primary or revision surgery, and the smoking status. The success rate of myringoplasty varies between $35-94 \%$ in children with follow-up ranging from 6 months to 1 year. ${ }^{5}$ The aim of this study is to evaluate the anatomical (postoperative graft uptake) and functional results (postoperative hearing improvement) after myringoplasty in adults and to find out the possible factors which affect these results.

\section{Methods}

This is a prospective study performed over a period of 18 months from October 2011 to April 2013. Patients of age $>13$ years with tubotympanic COM took part in this study. In our institution, patient $>13$ years of age are operated in the Otology Unit and patients $<13$ years are operated in the Pediatric Unit. In our center, we perform myringoplasty under local anesthesia because of high case load under general anesthesia. We obtained ethical clearance from the Institutional Review Board. We excluded patients with other middle ear pathology such as cholesteatoma, granulation tissue, extensive tympanosclerotic patch in the middle ear, patient undergoing combined procedure (cortical mastoidectomy, ossiculoplasty), myringoplasty using graft materials other than temporalis fascia, and patients with congenital craniofacial abnormalities. For hearing assessment, we excluded patients with immobile / disintegrated ossicular chain. We calculated the sample size using the Sample Size Calculator after reviewing the number of surgeries performed in previous years.

We obtained a detailed history and performed otoscopy and pure tone audiometry one week prior to surgery. We calculated average hearing threshold from $0.5,1,2,3$, and $4 \mathrm{KHz}$ frequencies and measured Air Bone Gap (ABG). Size of perforation was labeled as small if less than one quadrant of tympanic membrane was involved, medium if one to two quadrants of tympanic membrane was involved, and large if more than three quadrants of tympanic membrane were involved. ${ }^{7}$ In this study, we labeled the site of pars tensa perforation as anterior if perforation was anterior to line passing along the handle of malleus, posterior if perforation was lying posterior to this line, and subtotal if perforation involved both anterior and posterior portions of the pars tensa. ${ }^{8}$ We labeled tubotympanic COM as inactive if there was no otorrhea, active if there was discharge in the middle ear, and quiescent if there was absence of otorrhea for six weeks but middle ear inflammation had not settled completely.

We performed all surgeries under local anesthesia using 2\% Xylocaine with 1:2,00,000 adrenaline, infiltrated as four quadrant block in the external auditory canal and at the graft site. We pre-medicated patients using Pethidine $0.5-2 \mathrm{mg} / \mathrm{kg}$ and Promethazine $10-25 \mathrm{mg}$ injections intramuscularly in the deltoid region 30 to 60 minutes before surgery. We used the conventional underlay technique, harvesting the temporalis fascia as the graft material. Senior faculties ( $>5 \mathrm{yrs}$ experience), junior faculties ( $<5 y$ rs experience), and residents performed myringoplasties. Residents performed the surgical procedure under supervision of either senior or junior faculty who guided them orally, watching the monitor. Approach was either permeatal, postaural, or endaural. Patients were followed-up at one year for the graft uptake results. We reported any residual perforation ranging in size from pin-point perforation to total rejection as failure. Pure Tone Audiogram was done. We analyzed results for graft uptake in relation to different variables. Results for hearing was calculated in those who had normal ossicular status. We applied the chi-square test, Pearson's' correlation test, and logistic regression test for categorical variable and Paired $t$ test to analyze the hearing results on SPSS statistical package version 17.0. The level of statistical significance was set at $p<0.05$.

\section{Results}

The total number of patients enrolled for the study was 230 , out of which $11(4.7 \%)$ patients were lost to follow-up. Therefore, total number of patients included was 219. Graft uptake was observed in 182 out of 219 (83.1\%). Patients ranged in age from 13 to 62 years, with the mean age of $26.14 \pm 10.41$ years. There were total $99(45.2 \%)$ males and 120 (54.8\%) females. Ninety-eight (44.7\%) underwent right myringoplasty and 121 (55.3\%) underwent left myringoplasty.

The graft uptake results in relation to various factors are shown in - Table 1. Size and site of perforation, primary or revision myringoplasty, experience of surgeon, approach for surgery, status of middle ear during surgery, and smoking status were not found to be significant determining factor for successful myringoplasty. There were 54 patients between 13 to 18 years who underwent myringoplasty. Among them, 46 patients had graft uptake. We observed graft uptake in 136 out of 165 patients over 18 years of age. There was no significant difference in graft uptake in patients from the age group between 13-18 years and over 18 years. Graft uptake was higher in cases operated during summer season than in the winter, but the result was not statistically significant.

We found that 127 patients who underwent myringoplasty, had normal contralateral ear. Graft was taken up in 112 (88.2\%). 56 patients had tubotympanic chronic otitis media (COM) in the contralateral ear and graft was taken up in 42 patients (75\%). Graft uptake was significantly poor 
Table 1 Factors affecting success rate of myringoplasty

\begin{tabular}{|c|c|c|c|c|}
\hline Factors & Total patient & Graft taken up & $p$ value & Significance \\
\hline \multicolumn{5}{|l|}{ Age of patient } \\
\hline $13-18 \mathrm{yr}$ & 54 & 46 & \multirow[t]{2}{*}{0.638} & \multirow[t]{2}{*}{ NS } \\
\hline Adults (>18yr) & 165 & 136 & & \\
\hline \multicolumn{5}{|l|}{ Season } \\
\hline Summer & 153 & 128 & \multirow[t]{2}{*}{0.739} & \multirow[t]{2}{*}{ NS } \\
\hline Winter & 66 & 54 & & \\
\hline \multicolumn{5}{|l|}{ Size of perforation } \\
\hline Large & 165 & $136(82.4 \%)$ & \multirow[t]{3}{*}{0.566} & \multirow[t]{3}{*}{ NS } \\
\hline Medium & 52 & $44(84.6 \%)$ & & \\
\hline Small & 2 & $2(100 \%)$ & & \\
\hline \multicolumn{5}{|l|}{ Site of perforation } \\
\hline Subtotal & 198 & $165(83.3 \%)$ & \multirow[t]{3}{*}{0.709} & \multirow[t]{3}{*}{ NS } \\
\hline Anterior & 12 & $10(83.3 \%)$ & & \\
\hline Posterior & 9 & $7(77.7 \%)$ & & \\
\hline \multicolumn{5}{|l|}{ Primary/ Revision } \\
\hline Primary & 197 & $163(82.7 \%)$ & \multirow[t]{2}{*}{0.669} & \multirow[t]{2}{*}{ NS } \\
\hline Revision & 22 & $19(86.3 \%)$ & & \\
\hline \multicolumn{5}{|l|}{ Experience of surgeon } \\
\hline Senior faculty & 51 & $44(86.2 \%)$ & \multirow[t]{3}{*}{0.177} & \multirow[t]{3}{*}{ NS } \\
\hline Junior faculty & 102 & $87(85.2 \%)$ & & \\
\hline Resident & 66 & $51(77.2 \%)$ & & \\
\hline \multicolumn{5}{|l|}{ Approach } \\
\hline Permeatal & 166 & $136(81.9 \%)$ & \multirow[t]{3}{*}{0.406} & \multirow[t]{3}{*}{ NS } \\
\hline Postaural & 44 & $38(86.3 \%)$ & & \\
\hline Endaural & 9 & $8(88.8 \%)$ & & \\
\hline \multicolumn{5}{|l|}{ Status of middle ear } \\
\hline Dry & 179 & $150(83.7 \%)$ & \multirow[t]{3}{*}{0.773} & \multirow[t]{3}{*}{ NS } \\
\hline Quiescent & 32 & $26(81.2 \%)$ & & \\
\hline Active & 8 & $6(75 \%)$ & & \\
\hline \multicolumn{5}{|l|}{ Smoking status } \\
\hline Smoker & 20 & $16(80 \%)$ & \multirow[t]{2}{*}{0.447} & \multirow[t]{2}{*}{ NS } \\
\hline Non smoker & 199 & $166(83.4 \%)$ & & \\
\hline \multicolumn{5}{|c|}{ Status of contralateral ear } \\
\hline Normal & 127 & $112(88.2 \%)$ & 0.046 & $S$ \\
\hline COM Mucosal & 56 & $42(75 \%)$ & & \\
\hline Past Myringoplasty & 23 & $18(78.2 \%)$ & & \\
\hline Sequelae of OME & 13 & $10(76.9 \%)$ & & \\
\hline
\end{tabular}

Abbreviations: COM, Chronic Otitis Media; NS, Not significant; S, Significant.

when the contralateral ear had tubotympanic COM $(p<0.05)$.

We assessed a total of 132 patients with normal ossicular chain for hearing improvement after myringoplasty. The average pre-operative Air Conduction Threshold was $45.62 \mathrm{~dB}$ and the average post-operative Air Conduction Threshold improved to $34.17 \mathrm{~dB}$, which was statistically significant $(p<0.001)$. The average pre-operative Air Bone Gap was $30.08 \mathrm{~dB}$ and the postoperative Air Bone Gap was $21.18 \mathrm{~dB}$, which was statistically significant $(p<0.001)$, as shown in - Table 2 . 
Table 2 Hearing results after myringoplasty

\begin{tabular}{|l|l|l|l|}
\hline & Pre-operative & Post-operative & $p$ value \\
\hline Air Bone gap & $30.08 \mathrm{~dB}$ & $21.18 \mathrm{~dB}$ & $<0.001$ \\
\hline Air Conduction Threshold & $45.62 \mathrm{~dB}$ & $34.17 \mathrm{~dB}$ & $<0.001$ \\
\hline
\end{tabular}

During the study, we observed two cases of postaural wound infection and there were no cases of post-operative sensorineural hearing loss.

\section{Discussion}

Myringoplasty is the commonest otologic surgery performed in our center, with cases referred from all regions of the country. We included 230 myringoplasties using fascia graft with underlay technique for the study.

The success rate of myringoplasty ranges from $35 \%$ to $95 \%{ }^{5}$ The reason for such a wide array of reported success rates is mostly due to the large variety of non-standardized definitions of success, selection criteria, study designs, and lengths of postoperative follow-up; variables that make it very difficult to compare the different published success rates. ${ }^{9}$ In our study, we had a success rate of $83.1 \%$ at one year follow-up. The success rate in our study is comparable to that of Wasson et al who had $80.8 \%$ success at minimum three months follow-up in 130 cases. $^{10}$ The study by Gersdorff et al of 320 myringoplasties had a success rate of $87.7 \%$ after three years follow-up. ${ }^{11}$

There was no significant difference in graft uptake with the size of perforation in this study. Similar results has been shown by Calyan et al, Wasson et al, Gersdorff et al, Pignataro et al, and Denoyelle et al, where the size of perforation was not an important factor for successful myringoplasty. ${ }^{5,10-13}$ on the contrary, Lee et al achieved a success rate of $74 \%$ for small perforations (size less than $50 \%$ ) and $56 \%$ for large perforations (size greater than 50\%). ${ }^{14}$ Study by Kotecha et al and Onal et al have shown better graft uptake in small size perforation as compared with large perforation. ${ }^{15,16}$

There was no difference in graft uptake with the site of perforation in this study. This may be due to disproportionate patient distribution between the subgroups. A study by Kotecha et al and Kumar et al found poorer success rate of myringoplasty in anterior perforation. ${ }^{15,17}$ This has been attributed to technical challenge to repair due to poor visibility of anterior margin of perforation, more difficult access, inadequate graft support, and relatively poorer perfusion in anterior portion of tympanic membrane. ${ }^{15}$ A study by Koch et al found results of the posterior perforation poorer than the anterior one. ${ }^{18}$ Most of the recent studies have found that the site of perforation is not a determining factor for successful myringoplasty. $5,12,19-21$

The graft uptake for myringoplasty done by the senior faculty was $86.2 \%$, by the junior faculty was $85.2 \%$, and by residents was only $77.2 \%$. The result was however not statistically significant. This may be because the number of cases done by junior faculty (102) is double that done by senior faculty (51) and residents (66). Onal et al, Vartiainen et al, and Black \& Wormald have reported inferior success rates for junior surgeons as compared with senior surgeons. ${ }^{16,19,22}$ Emir et al, in his 607 patients with at least 12 months of follow-up found that the graft uptake for residents was $86.2 \%$, whereas, for the senior faculty, it was $94.8 \%(p=0.007) .{ }^{23}$ In our institution, myringoplasty is the first middle ear surgery allowed to be performed by the resident under the guidance of faculty from the Otology Unit. Studies by Wasson et al, Lee et al, Kumar et al, and Palva et al have not found the experience of surgeon to be an important factor for successful myringoplasty. ${ }^{10,14,17,24}$

We operated 166 cases by permeatal approach. Graft uptake was 136 (81.9\%). We operated 44 cases by postaural approach and graft uptake was 38 (86.3\%). We operated 9 cases by endaural approach and 8 had graft uptake (88.8\%). The graft uptake with various approaches was not statistically significant. Most of myringoplasty in our setup is done via permeate/transcanal approach. Cases with poor visibility of anterior margin of perforation, narrow canal, and large size perforation undergo the postaural approach. Studies by Pignataro et al and Fransisco et al have not found statistically significant differences in the success rate in terms of the surgical approach, as in this study. ${ }^{12,20}$

The graft uptake was $83.7 \%$ in dry ear, $81.2 \%$ in quiescent ear, and $75 \%$ in actively discharging ear. The result was, however, statistically not significant because of disproportionate case distribution between the subgroups. Studies by Pignataro et al, Denoyelle et al, and Lau \& Tos have shown graft uptake results better in dry ears as compared with wet ears. ${ }^{12,13,25}$ Denoyelle found that the inflammatory changes within the middle ear mucosa independently influenced the risk of abnormal postoperative tympanic membrane. ${ }^{13}$ However, study by Calyan et al claim better graft take rates in wet ears as compared with dry ears because of increased vascularity. ${ }^{5}$ Many studies like Knapik M., Kotecha et al, Onal et al, and Vartiainen et al, have not considered the perioperative condition of the middle ear as a prognostic factor in myringoplasty. $9,15,16,19$

In this study, we found the status of the contralateral ear to be an important prognostic factor for graft uptake. Graft uptake was significantly poor when the contralateral ear had tubotympanic COM $(p<0.05)$. We found similar results in the studies by Calyan et al, Gersdorff et al, Onal et al, Koch et al, Fransisco et al, and Ophir et al. ${ }^{5,11,16,18,20,26}$ This finding might indicate an Eustachian tube dysfunction and the tendency of chronic otitis media to present as a bilateral disease. ${ }^{16}$ The status of contralateral ear is important in two aspects: first, in its contribution for understanding the pathogenesis of otitis media, and second, in its implications in 
treatment and counselling. However, other studies by Pignataro et al, Koch et al, and Albera et al have not found the diseased contralateral ear to be an important prognostic factor for successful graft uptake in myringoplasty. ${ }^{12,18,27}$

Studies have shown no significant impact on surgical success in primary or revision myringoplasties by Wasson et al, Lee et al, and Vartiainen et al. ${ }^{10,14,19}$ The higher graft uptake rate in revision cases in this study may be because of cases being performed by the faculties.

In this study, 199 patients were non-smokers and 20 patients were smokers. The graft uptake in non-smoking group was $83.4 \%$ and that in the smoking group was $80 \%$. This difference was not statistically significant, likely due to a disproportionate population within the subgroup. However, we did not take into account details of amount and duration of smoking in this study. In a study by Onal et al in 80 myringoplasties, they had a success rate of $78.7 \%$ in the non-smoking group and $47.7 \%$ in the smoking group $(p=0.008) .{ }^{16}$ Smoking changes the amount and viscosity of mucous and destroys the ciliated epithelium of the Eustachian tube and middle ear mucosa. ${ }^{16}$ Nicotine causes cutaneous vasoconstriction, promotes thrombosis, and carbon monoxide inhaled in cigarette smoke also reduces the oxygen-carrying capacity of the blood, which in turn causes inadequate oxygenation of the graft. These factors may impair the graft vascularization. The systemic effects of smoking are the chemoallergic and immunosuppressive properties that may cause increased susceptibility to the infectious agents and thereby lead to graft failure. ${ }^{16}$ However, a study by Wasson et al did not find smoking to be a significant factor for successful myringoplasty. ${ }^{10}$

Hearing improvement after myringoplasty is statistically significant if the ossicles are normal. We found similar results in a study done by Wasson et al and Vartiainen et al. ${ }^{10,19}$

Most of the studies have shown short term graft uptake results of myringoplasty. In this study, we followed up the patient for one year to study the long term uptake result of the fascia graft. A larger and proportionate sample size would yield a stronger study.

\section{Conclusion}

Diseased contralateral ear was a statistically significant poor prognostic factor for successful myringoplasty. Other factors such as site and size of perforation, smoking status, revision surgery, status of middle ear, experience of surgeon, and surgical approach were not statistically significant prognostic factors for successful myringoplasty.

\section{References}

1 Browning GG, Merchant SN, Kelly G, Swan IR, Canter R, McKerro WS. Chronic otitis media. In: Gleeson M, editor. Scott-Brown's Otorhinolaryngology, Head and Neck Surgery. 7th ed. Vol 3. London: Edward Arnold; 2008:3345-95

2 Berman S. Otitis media in developing countries. Pediatrics 1995; 96(1 Pt 1):126-131
3 Little P, Bridges A, Guragain R, Friedman D, Prasad R, Weir N. Hearing impairment and ear pathology in Nepal. J Laryngol Otol 1993;107(5):395-400

4 Manolidis S. Closure of tympanic membrane perforations. In: Glasscock ME, editor. Glasscock-Shambaugh's Surgery of the Ear. 5th ed. Hamilton: BC Decker; 2003:400-19

5 Caylan R, Titiz A, Falcioni M, et al. Myringoplasty in children: factors influencing surgical outcome. Otolaryngol Head Neck Surg 1998;118(5):709-713

6 Golz A, Goldenberg D, Netzer A, et al. Paper patching for chronic tympanic membrane perforations. Otolaryngol Head Neck Surg 2003;128(4):565-570

7 Sakagami M, Yuasa R, Yuasa Y. Simple underlay myringoplasty. J Laryngol Otol 2007;121(9):840-844

8 Ashfaq M, Aasim UM, Khan N. Myringoplasty: Anatomical and functional results. Pak Armed Forces Med J 2004;54(2):155-158

9 Knapik M, Saliba I. Pediatric myringoplasty: a study of factors affecting outcome. Int J Pediatr Otorhinolaryngol 2011;75(6): 818-823

10 Wasson JD, Papadimitriou CE, Pau H. Myringoplasty: impact of perforation size on closure and audiological improvement. J Laryngol Otol 2009;123(9):973-977

11 Gersdorff M, Garin P, Decat M, Juantegui M. Myringoplasty: longterm results in adults and children. Am J Otol 1995;16(4):532-535

12 Pignataro L, Grillo Della Berta L, Capaccio P, Zaghis A. Myringoplasty in children: anatomical and functional results. J Laryngol Otol 2001;115(5):369-373

13 Denoyelle F, Roger G, Chauvin P, Garabedian EN. Myringoplasty in children: predictive factors of outcome. Laryngoscope 1999; 109(1):47-51

14 Lee P, Kelly G, Mills RP. Myringoplasty: does the size of the perforation matter? Clin Otolaryngol Allied Sci 2002;27(5):331-334

15 Kotecha B, Fowler S, Topham J. Myringoplasty: a prospective audit study. Clin Otolaryngol Allied Sci 1999;24(2):126-129

16 Onal K, Uguz MZ, Kazikdas KC, Gursoy ST, Gokce H. A multivariate analysis of otological, surgical and patient-related factors in determining success in myringoplasty. Clin Otolaryngol 2005; 30(2):115-120

17 Kumar S, Acharya A, Hadjihannas E, Panagamuwa C, McDermott AL. Pediatric myringoplasty: definition of "success" and factors affecting outcome. Otol Neurotol 2010;31(9):1417-1420

18 Koch WM, Friedman EM, McGill TJI, Healy GB. Tympanoplasty in children. The Boston Children's Hospital experience. Arch Otolaryngol Head Neck Surg 1990;116(1):35-40

19 Vartiainen E, Nuutinen J. Success and pitfalls in myringoplasty: follow-up study of 404 cases. Am J Otol 1993;14(3):301-305

20 Avilés Jurado FJ, Merán Gil JL, Tobed Secall M, et al. Myringoplasty: auditory follow-up and study of prognostic factors. Acta Otorrinolaringol Esp 2009;60(3):169-175

21 Kessler A, Potsic WP, Marsh RR. Type 1 tympanoplasty in children. Arch Otolaryngol Head Neck Surg 1994;120(5):487-490

22 Black JH, Wormald PJ. Myringoplasty: effects on hearing and contributing factors. S Afr Med J 1995;85(1):41-43

23 Emir H, Ceylan K, Kizilkaya Z, Gocmen H, Uzunkulaoglu H, Samim E. Success is a matter of experience: type 1 tympanoplasty : influencing factors on type 1 tympanoplasty. Eur Arch Otorhinolaryngol 2007;264(6):595-599

24 Palva T, Ramsay H. Myringoplasty and tympanoplasty-results related to training and experience. Clin Otolaryngol Allied Sci 1995;20(4):329-335

25 Lau T, Tos M. Tympanoplasty in children. An analysis of late results. Am J Otol 1986;7(1):55-59

26 Ophir D, Porat M, Marshak G. Myringoplasty in the pediatric population. Arch Otolaryngol Head Neck Surg 1987;113(12):1288-1290

27 Albera R, Ferrero V, Lacilla M, Canale A. Tympanic reperforation in myringoplasty: evaluation of prognostic factors. Ann Otol Rhinol Laryngol 2006;115(12):875-879 